\title{
ENTRE PODER, HEREJÍA Y SALVACIÓN. LA VIRGEN A FINALES DEL SIGLO XVII A TRAVÉS DE LA MÍSTICA CIUDAD DE DIOS DE MARÍA DE ÁGREDA
}

\author{
RUTH BERTOMEU MUÑOZ \\ EHESS - París
}

Recibido: $13 / 8 / 2012$

Aceptado: 08/10/2012

\section{Resumen}

La mística ciudad de Dios, obra clave de María Coronel de Ágreda, intentó dar respuesta a uno de los temas más controvertidos de la historia de la Iglesia católica, la vida de la Virgen María. Tanto esta obra como su autora formaron parte de una controversia que se tradujo en la censura de la misma en 1696 por la Universidad de la Sorbona de París. Esta censura provocó que el papel de la Virgen María se volviese a pensar convirtiéndose en una problemática a fines del siglo XVII.

Palabras clave: Iglesia Católica, Virgen Maria, controversia, María Coronel de Ágreda

\begin{abstract}
The mystic city of God, key work of Maria Coronel de Ágreda, religious of Concepcionist Convent of Agreda, tried to give answer to the one of the most controverst subject of the catholic church story, the Virgin's Mary life. As much work as her author take part of a controversy that it translated of the immediate cersorship of the work in 1696 for the Sorbona University of Paris. This censorship cause that the part of the Virgin's Mary it returns to take becoming in a problem at the end of the $17^{\text {th }}$ century.
\end{abstract}

Keywords: Catholic Churc, Virgin’s Mary, controverst, Mary Coronel de Ágreda 

[...] y conozco intelectualmente todos los Mysterios, y Sacramentos,

que se me muestran de la vida de la Reyna de el Cielo, y otros muchos de la Fè, que casi incessantemente tengo presentes: alomenos

la luz nunca la pierdo de vista ${ }^{1}$.

María Coronel de Arana (MDA a partir de ahora), más conocida como María de Ágreda (1602-1665) religiosa del Convento de las Madres Concepcionistas de Ágreda, fundado en 1619, fue una de las mujeres que ocupó y ocupa un lugar predominante tanto en la historia de la religiosidad, como en la de las mujeres escritoras.

Desde muy joven tuvo un contacto muy fuerte con la vida religiosa, ya que su familia así lo había querido, su madre fundó el convento en su misma casa del cual ella sería abadesa a la edad de 24 años y tanto su padre como su hermano partieron con los hermanos franciscanos. Aparte de estar rodeada de personas creyentes y de tener una vida profundamente religiosa, fue más lejos experimentando diversos episodios de éxtasis que más tarde la harían célebre. Fue al sentir ese contacto más directo con la divinidad el que la obligó, primero a entrar en el convento a una edad muy temprana y seguidamente a escribir lo que veía y sentía. Podemos decir que tuvo desde joven una inagotable vida de escritora.

Escribió obras para las religiosas que ingresaban en el convento y otras tantas sobre el tema que más le interesaba, la Inmaculada Concepción; pero la más extensa, importante por el tema tratado y discutida por teólogos y estudiosos, fue la La mística ciudad de dios² (MCD a partir de ahora).

1. ÁGReDA, María de. La mística ciudad de Dios, p. 16.

2. El título es bastante extenso y deja ver claramente el fin del mismo: Mística ciudad de Dios. Milagro de su omnipotencia y Abismo de la Gracia. Historia divina y vida de la Virgen Madre de Dios, Reina y Señora nuestra, María Santísima, Restauradora de la culpa de Eva y Medianera de la Gracia. Dictada y manifestada en estos últimos siglos por la misma señora a su esclava Sor María de Jesús, Abadesa indigna de este convento de la Inmaculada Concepción de la villa de Ágreda. Para nueva luz del mundo, alegría de la Iglesia católica y confianza de los mortales». Madrid, 1670. 
La obra más importante de MDA, la MCD se convirtió desde el momento de su impresión en 1670 en un libro no ya esperado por la persona que firmaba dicho libro, sino por el sujeto que contenía. Estos hechos fueron los que llevaron a la MCD a parar a manos de la Inquisición española para poder ser estudiado durante siete años. De ahí pasó a Roma para terminar en París, que es donde se centra nuestro objeto de estudio.

Pero, ¿cuál fue la razón de esta fijación por el estudio del libro? Para empezar, está el texto de MDA y su celebridad en España. Debemos recordar que mantuvo una gran correspondencia de veinte años, con Felipe IV además de otros personajes ilustres. La concepcionista era además una mujer al tanto de todas «las novedades» que acontecían por el país.

Aparte de ello, el halo místico que la rodeaba y los famosos casos de bilocación a las Américas con el propósito de evangelizar a los indios fueron los primeros acontecimientos que la llevaron a ser una persona vigilada por el Santo Oficio. Hasta llegar a la polémica redacción de su obra magna, la MCD, obra que fue quemada primeramente por orden de un confesor provisional y que más tarde la reescribirá gracias al ánimo de su confesor.

El comienzo de la gran importancia de esta obra empieza aquí, importancia que continuará primero sabiendo que ha sido inspirada por Dios y seguidamente que es la vida de la Virgen María.

Es a partir de la redacción de esta obra y su posterior acogida tanto en España como en países extranjeros, y el controvertido papel de la Virgen, lo que nos obliga a intentar responder a la pregunta de que si la Virgen es sinónimo de salvación y de mediación entre el mundo de las mujeres y de los hombres, por qué, una obra que trata de la misma fue objeto de una censura por parte de una de las universidades con más prestigio y poder, la Sorbona. Y cómo este acontecimiento, llamado posteriormente controversia, se convirtió en un suceso internacional en el que participaron personajes tan importantes como Bossuet, varios papas, universidades como la de Salamanca, Lovaina, Alcalá de Henares y las más altas personalidades españolas.

Es el controvertido tema de la Virgen María, no sólo a finales del siglo XVII sino en el libro mismo y el efecto que causa una censura lo que nos hace ver cómo la figura de la Virgen forma de manera indirecta parte de la herejía.

¿Qué conllevaba el ser acusada/o de hereje? Ser acusada/o de herejía significaba haber hecho una elección, es decir, haberse posicionado en contra de los dogmas católicos o peor aún, rehusar de ellos y de la misma Iglesia. Era también un sistema de creencias contrarias a lo establecido. Ahora, ¿cumplía MDA estas características? 
Para poder responder a nuestras preguntas, dividiremos nuestro trabajo en cuatro partes. Para empezar, una explicación sobre el rol que ha ocupado la Virgen durante la historia y su contacto con las religiosas es crucial para comprender, en una segunda parte, lo que significó la Virgen para nuestra autora. Seguidamente saber cuál fue el papel de la Sorbona de París frente al libro y por último, qué puntos fueron los más problemáticos a la hora de censurar.

Intentaremos ver gracias a estos puntos como se llega a un momento en los hechos que acontecen tanto en la censura de la obra como en la obra misma un cambio de posición que obligan a que la Virgen se encuentre en la difícil encrucijada de la salvación y de la herejía.

En esta encrucijada tenemos de un lado la censura. Ésta hace que tanto MDA, su obra y la Virgen formen parte del mundo de la herejía. Pero por otro lado nos encontramos lo que MDA pensaba y puso por escrito sobre la Virgen y el significado espiritual de esta figura. Con MDA la Virgen sufre una elevación de poder inmensa. Es por ello que estos dos «mundos» tan diferenciados nos hacen preguntarnos sobre el papel de María dentro del seno de la Iglesia, su evolución en ella y en la historia y más importante aún, dentro de la MCD. Sabiendo esto podremos llegar a una reflexión, lo que pensaba MDA era realmente una herejía, ¿estaba en contra de lo que propugnaba la Iglesia?

El problema historiográfico que existe sobre el papel de la Virgen a fines del XVII sigue en pie: ¿disminuyó su devoción o siguió estando en alza?

\section{El papel y el rol de la Virgen en la época moderna}

El papel y el rol de la Virgen se ha ido construyendo durante todos estos siglos, no es una figura clara ya que lo que se sabía sobre la madre del Mesías era muy poco. Esto a dio lugar a que su figura como mujer, como Virgen y como madre no haya cesado de evolucionar gracias a «las aspiraciones de los fieles y al peso inevitable del contexto tanto espiritual y teológico como político, social y económico» ${ }^{3}$. De ahí que la Virgen María se haya convertido en uno de los personajes que no ha parado de ser meditado y reflexionado, como dice Annick Delfosse, es una figura polimorfa ${ }^{4}$. Esas diferentes y variadas formas empezaron a dárselas para poder construir a alguien que tuvo un gran peso dentro de la historia de la Iglesia pero que al principio carecía del mismo ${ }^{5}$. Esta construcción podría ser vista como una «necesidad» por parte de los fieles

3. DELFOSSE, Annick. «La Vierge Marie, une figure polymorphe du catholicisme». Dossiers de la Bibliothèque royale de Belgique, 26 (2005), pp. 75-96.

4. Ibid., p. 75.

5. Los mismos diccionarios de teología y espiritualidad lo afirman: no se puede deducir nada sólido y en claro en teología mariana. 
o de las religiosas o religiosos al no entender como una persona como María era apenas nombrada en las Escrituras.

Esto es constatado por ejemplo en el Nuevo Testamento, donde la importancia de María se traducía en ser la madre del mesías. Su papel dentro de la salvación era nulo y por supuesto, no se encontraba en la misma escala que Jesús, es más, estaba por debajo ${ }^{6}$. Es en el Evangelio de Lucas donde ella tiene algo más de importancia ya que es presentada como una persona llena de «gracia $»^{7}$ por obra de Dios.

Es bastante interesante leer lo escrito en los Evangelios Apócrifos ya que narran la vida de la Virgen como un ser humano, una "heroína con cualidades excepcionales que le atribuyen una familia, unos orígenes y un carácter particular $[\ldots] »^{8}$.

Son esas cualidades excepcionales que también Orígenes le atribuyó, para él ella era un modelo virginal a seguir y una persona que hizo progresos en la vida espiritual. Todo esto llevó a que su devoción comenzase, primero en Oriente y más tarde en Occidente, siendo la época medieval el periodo importante ya que su imagen de Virgen y mujer comienzan a hacerla visible por méritos propios. En el siglo XI se muestra una devoción a María creciente y evolutiva. En los siglos XII y XIII ésta no deja de evolucionar por el cuestionamiento de temas vitales con el fin de comprender su rol dentro de la vida espiritual así como de la Iglesia. En la segunda mitad del siglo XVII las dudas sobre la devoción y sobre su rol de mediación continúan preguntándose. Pero llega un momento en el que María y Dios se unen, haciendo que la vida de los cristianos y cristianas sea más «fácil», ya que uno de los caminos para llegar a Dios es gracias a María. El ejemplo más cercano a este acontecimiento es el gran auge de los carmelitas y las/os místicas/os que favorecen esta unión, es el momento en el que María hace un papel mucho más visible de mediadora entre el alma cristiana y Dios.

En fin, desde la época medieval hasta el siglo XVIII se produce una fuerte feminización en la Iglesia en la figura de la Virgen. Su figura es central ya que tiene omnipresencia y visibilidad ${ }^{9}$. Esta feminización no es visible por ejemplo en las peregrinaciones a la misma Virgen ya que no se ven apenas mujeres, pero existe de todas formas, en el mundo conventual un reclamo. Lo podemos ver perfectamente en los libros escritos por las religiosas donde encontramos

6. DeLFOSSE, Annick. Op.cit.p. 81

7. El término «gracia» aludía a una asimilación muy óptima de los dogmas autorizados éstos por la fe.

8. Delfosse, Annick. Op.cit., p. 76.

9. Delfosse, Annick. Op.cit., p. 78. 
un contacto, un llamamiento de mujer a mujer, de madre a hija o de hermana a hermana.

La Virgen no deja de ser divina, no deja de ser Diosa, es por ello que estos títulos permiten que haya diferencias entre ella y las mujeres que le rendían culto. La Virgen se encuentra en un nivel superior y tiene una serie de cualidades que la hacen Maestra, Reina o Diosa. Estas cualidades son la Inmaculada concepción o su Asunción. Pero estas facultades no la hacen inaccesible, el ejemplo más cercano es nuestra autora, para MDA ella se presenta al lado de Dios para ser una Maestra y una madre, para ser una guía y para ir en su ayuda a la hora, por ejemplo, de escribir.

\section{El contacto con lo divino}

El efecto más directo para huir del mundo terrenal y ver más allá así como el tener un contacto más deseado con los personajes divinos fue la mística. Ésta se encargará de aumentar de formas diversas el poder de la Virgen, ya que para las religiosas y los religiosos existía otro modo de llegar a lo «más alto» y ese modo estaba presentado bajo la forma de la Virgen María.

Para poder llegar a ese «mundo superior», a ese cielo etéreo, se tenía que producir un contacto más directo con lo divino y los seres que lo rodeaban que se traducía para las místicas y los místicos en una especie de amor superior que rebasaba los límites de conocible: «leur union amoreuse et érotique s'est élevée au-dessus du monde contraignant des lois sociales et ecclésiastiques» ${ }^{10}$.

Se le daba una importancia sublime a la imaginación, a la percepción, al quietismo para poder llegar a ese «éxtasis» ansiado, querido y deseado.

Esta unión podría ser vista, desde el punto de las mujeres, como el culmen de su matrimonio sagrado, ellas se veían como las esposas vírgenes. El ejemplo más cercano lo encontramos en nuestra autora, MDA en su obra no deja de verse como la esposa cristiana.

Este contacto con lo divino no se traduce solamente en un «matrimonio» entre las religiosas y Dios sino que muchas veces estos contactos aportaban algo más a la mística o al místico, aportaban conocimiento y claridad sobre lo que no se llegaba a entender. Esta comunicación era vista como la necesidad de lo Divino para explicar sus deseos que estaban traducidos en «misterios» y «revelaciones». Las revelaciones de los misterios impulsaban a muchas y a muchos a dejarlos por escrito con el fin de hacerlos más comprensibles, esto proporcionaba a muchas religiosas una vida intelectual activa, ya que

10. Duby, Georges; Perrot, Michelle, Histoire des femmes en Occident. Vol. 3, Paris, Perrin, 2002, p. 200. 
era una necesidad, un deber y hasta una obligación escribir las cosas divinas. Es gracias a la mística que se consigue este fin, el conocimiento del misterio, en palabras de Pseudo-Denis es «la necesidad de ir más allá de las imágenes, las figuras así como los conceptos para poder esperar lo absoluto en la unión mística» ${ }^{11}$.

Este es el punto de partida de la obra de MDA. Para empezar, lo que hace ella es lo que harán muchas otras místicas, revelar lo no revelado, escribir lo que no está escrito y poder entender lo que hasta ese momento no era entendible. Lo más importante de la obra de MDA es que se atreve con uno de los misterios más importantes en la historia de la Iglesia, la vida de la Virgen y todo lo que ella conlleva. En la Virgen se encuentra el primer misterio y para MDA todos los demás «(...) la misma Señora Reyna, y Madre nuestra que fue capaz de recibir tan inefables dones, y digna de conocerlos» ${ }^{12}$. Según ella y lo vemos por escrito en su Introducción a la obra, ella escribe porque está obligada tanto por Dios como por la Virgen a revelar dicho secreto. Ella será objeto de todo lo divino para poder obrar como ellos desean «El mismo Señor sabe porque, y para que à mi la màs vil criatura me derpertò, llamò y levantò, y me dispuso, y encaminò, me obligò, y compeliò à que escriba la vida de su digna Madre, Reyna, y Señora nuestra» ${ }^{13}$.

He aquí el comienzo de una serie de caminos y de hechos que terminarán con una serie de conclusiones diferentes. Desde que se supo de la obra, de quién había sido escrita y más aún, que ésta había sido revelada las autoridades eclesiásticas se dedican a estudiarla. Primero por la Inquisición española, que estuvo durante siete años haciendo su estudio mientras que en Roma y en París dichos estudios habían sido más rápidos, sin duda alguna ésta pasaba a ser censurada. Después de que la noticia llegase a España, las autoridades españolas entablan conversaciones con Roma para poder eliminar el libro de una de las autoras españolas más importantes del Índice de Libros Prohibidos. Roma acata las órdenes y desaparece del Índice rápidamente. Pero esta rápida desaparición del libro dará que hablar entre los eruditos franceses cuando la censura de la Facultad de París se haga efectiva. Es ésta última censura, la francesa, la que nos interesa estudiar ya que la fecha de la censura coincide con una época bastante convulsa en Francia, véase la crisis quietista y de conciencia que provocan que temas como el de la Virgen cobren una importancia

11. Derville, A; Lamarche, P; Solignac, A. Dictionnaire de spiritualité ascétique et mystique. Paris, Beauchesne, 1995.

12. ÁGREDA, María de. Mística ciudad de Dios. p. 1.

13. Íbid, p. 2. 
máxima por lo que el libro de MDA no hizo más que reabrir un debate sobre su rol y volver a reafirmar la hegemonía de la Virgen.

\section{2. ¿Qué significaba la Virgen para la Madre Ágreda?}

Desde que escribió y terminó su obra ella comprendió lo que dicho libro significaba y significaría ya que de una cosa estaba segura, sus revelaciones no debían verse como «simples visiones» sino como una constante e infalible verdad $^{14}$. Deja aún más claro el fin de esta obra, que no es sólo dar a conocer la vida de la Virgen sino que con este conocimiento revelado se intenta salvar a la humanidad. Véase la importancia de la Virgen, de su intercesión y de su rol, en ella se encuentra la salvación eterna. Idea que ya se discutió en el Concilio de Trento donde se le atribuyó «funciones protectoras sobre la Iglesia, las órdenes religiosas así como sobre los Estados católicos y se desarrolló una espiritualidad donde su figura era necesaria para la Salvación $»^{15}$. A pesar de que lo que dijese MDA no fuese una novedad, fue censurada.

Entre otras funciones para la Madre Ágreda, María representaba el principio de un todo y el principio de una Institución, es en su imagen «donde están encerrados, depositados, y sellados los Mysterios maravillosos de la Redención ${ }^{16}$. De ahí que a pesar de que MDA siga los dictámenes de Dios, la principal protagonista es la Virgen porque es de ella de la que se habla, a pesar de que en palabras de Dios se diga: «te señalo por maestra a mi Madre, y Virgen: ella te industriará, y encaminará sus pasos à mi agrado y beneplacito ${ }^{17}$. Es gracias a ella también que MDA vuelve a escribir por segunda vez la MCD, María, la Virgen, le dice: «trabaja fiel, y diligente por imitarme, ser perfectisima hija mia engendrada de mi espiritu, criada a mis pechos. Yo te doy mi bendición para que en mi nombre, y con mi dirección, y asistencia escribas por segunda vez» ${ }^{18}$.

Es vista además como la «Reyna de todo lo criado» ${ }^{19}$, no deja de repetir que es la reina, la gobernadora del Universo, del Cielo y más importante aún, de la Iglesia. La describe además como «Pura, Grande, Mistica y Divina criatura, màs para ser admirada con alabança de todas las demàs, que para ser

14. Ibid, p. 16.

15. DELFOSSE, Annick. «La Vierge comme protectrice des Pays-Bas méridionaux dans les livrets de pèlerinage marial au XVIIe siècle». Revue Belge Philologie Histoir 80 (2002), pp. 1225-1241.

16. Ágreda, María de. Mística ciudad de Dios... p. 11.

17. Ibidem.

18. Ibid, p. 7.

19. Íbid, p. 12

Feminismo/s 20, diciembre 2012, pp. 297-313 
descripta de ninguna $»^{20}$. Es una devoción que rebasa todos los límites, eso es lo que sentía nuestra religiosa por la Virgen, y más para solicitar «[...] la intercession de la Reyna, y Virgen Pura, suplicandole con todo mi coraçon me guie, y encamine por un camino recto, y oculto à los ojos de los hombres» ${ }^{21}$.

Pero lo que pensaba y sentía MDA de la Virgen María fue interpretado de manera muy diferente en una de las Universidades con más influencia en la época moderna, la Sorbona de París.

\section{El papel de la Facultad de Teología de la Sorbona de París}

Estas diferentes interpretaciones fueron puestas por escrito en una censura publicada en 1696. Decir ante todo que era una obra esperada, ya que cuando ésta se publica en Madrid habiendo ya fallecido nuestra religiosa, pasa a ser traducida rápidamente por un recoleto, Thomas Croset ${ }^{22}$. Será traducida por la fuerte demanda que existe en el país vecino de leer a MDA que había muerto en olor de santidad y que tenía una celebridad que había pasado fronteras. La MCD se publica primero en Portugal y después en Marsella en 1695 con privilegio del rey. Un año más tarde y con gran rapidez, como habíamos comentado, se censura por la Facultad de Teología de la Universidad de París.

Entre las causas encontramos varias, ya que creemos que en vez de una, fueron una serie de elementos los que podían haber formado parte de la censura. Para empezar la época, los años finales del siglo XVII no eran buenos para la publicación de libros «revelados» o místicos. En Francia, concretamente, se vivía una desconfianza a la mística venida de la crisis quietista donde Fenelon y Madame De Guyon eran sus máximos representantes. Otra de las causas era que el gobierno de Luis XIV tampoco ayudaba en la promoción de los libros, ya que el control excesivo que se ejercía sobre las impresiones de éstos no hacía más que aumentar las censuras y la desconfianza, siendo los libros religiosos los más vigilados y censurados. También, el galicanismo, ese deseo por parte del gobierno francés de poder independizarse religiosamente de Roma no hicieron más que poner en evidencia las relaciones difíciles con el Papa. Relaciones que afectaron también al libro de MDA, ya que se intentó efusivamente por parte de España que Roma interviniese en esta causa que se veía perdida. También en las mismas asambleas los partidarios de MDA

20. Íbid, p. 22.

21. Íbid, p. 14.

22. Thomas Croset sabía perfectamente español, fue gracias al impulso de otros religiosos y religiosas que decidió traducir la obra. A pesar de que fuera censurada él no dejará de hacer lo posible por mostrar que MDA no cometió ninguna herejía, sino todo lo contrario. 
alegaban que debía seguirse el ejemplo de Roma, ya que ésta había retirado la obra del Índice de Libros Prohibidos así como su censura.

De todas formas podemos decir que una de las causas sobresale entre todas, y es la controversia en torno a todo lo que tiene que ver con la censura, véase los doctores que participaron, la manera rápida de censurar, las asambleas difíciles que se vivieron en las que la lucha entre las órdenes religiosas por defender el libro de una parte, y de otras por censurarlo, estaban plagadas de tensiones, así como la hipótesis de que uno de las personalidades más importantes de Francia, Bossuet, había sido el causante de mostrar el libro a la Facultad y hacer lo posible para censurarlo ${ }^{23}$.

Sería conveniente abordar más el tema de la controversia pero es un tema arduo y extenso. Nuestro trabajo aquí es ver como la imagen de la Virgen se «trastoca», como su figura pasa a estar en lo más alto a ser objeto de una herejía.

Para empezar según la censura, MDA no comete una herejía, sino dos. La primera es elevar la dignidad de la Virgen de manera excesiva y la segunda herejía se cumple siguiendo la primera, es decir, al «elevarla», disminuye su dignidad. Ser condenado/a de herejía suponía acusar a los autores o autoras de ir en contra de los dogmas católicos así como de los misterios revelados como bien habíamos dicho anteriormente. Las autoridades eclesiásticas a través de las Universidades intentaban poner las bases y los límites a lo que se imprimía y se leía. Era la labor que desempeñaban aparte de enseñar, clarificar los misterios y revelaciones en base a las escrituras y los dogmas. Su labor era, en palabras de Alphonse Dupront en su obra L'erreur et son juge «de buscar el error $»^{24}$ en las obras a analizar sabiendo que encontrando el «error» encontrarían la verdad. Estos actos también eran supervisados por las autoridades políticas, es decir, en el periodo de Luis XIV la Universidad de la Sorbona se encuentra muy influenciada por el galicanismo conviertiéndose los Doctores en personas «très mefiants devant les jésuites, devant toutes les nouveautés philosophiques ou religieuses ${ }^{25}$. Los doctores encargados de ese trabajo estaban bajo el mando político y no bajo su opinión religiosa frente a los libros.

Antes de poner en relieve sus herejías, la Facultad de Teología se ve obligada a publicar junto con la censura, un manifiesto. Dicho manifiesto tiene

23. Diversas fuentes francesas lo nombran como el primer causante de la controversia ya que tenía especial relación con los Doctores que se dedicaron a censurar la obra.

24. NEVEU, Bruno. L'erreur et son juge, Naples, Bibliópolis, 1993.

25. LE BRUN, Jacques: «Censure préventive et littérature religieuse en France au début du XVIIIe siècle», Revue d'histoire religieuse de l'Église de France. Tome 61. № 167 (1995), pp. 201-225. 
que ver con la «verdadera» creencia y devoción que los fieles deben tener a la Virgen y la creencia que se supone, tiene la Sorbona sobre ella.

Podemos leer que «La Faculté a cru devoir faire une déclaration publique, qu'elle ne prétend pas par cette censure, rien diminuer du véritable E légitime culte que l'Église Catholique rend par toute la Terre à la très-Sainte Vierge (...) $»^{26}$. Es una frase que intenta de una manera, excusarse de la censura publicada ya que podríamos pensar que los Doctores que se encargaron de esta gesta se pudiesen sentir atacados por otros doctores, por Roma o incluso por otras Universidades ${ }^{27}$. Por otra parte también puede querer asentar y dejar claros, el «verdadero» culto, poder y papel de la Virgen dentro de la Iglesia, es decir, sentar los límites del poder de la Virgen como madre del mesías. Podemos intuir claramente la posición de estos Doctores. Antes de nada, queremos aclarar que no queremos englobar a toda la Sorbona en la época moderna de este pensamiento respecto a la Virgen sino a un grupo de doctores de la misma Facultad. He aquí otro punto más para poder reafirmar la controversia.

Es en esta introducción donde aparece el «error» de MDA, el por qué de su censura, es decir, su herejía. Como habíamos dicho antes, MDA en palabras de los Doctores había cometido un «exceso» «Ce dernier excès, par lequel on éleve la dignité de la Sainte Vierge au dessus des regles, est ordinairement un ouvrage de femme, \& est soutenu par ce sexe» ${ }^{28}$. Es interesante como se deja ver el antifeminismo, no sólo de los Doctores sino de la Sorbona en sí ${ }^{29}$. Este carácter antifeminista, acorde también con la época y más con los libros escritos por mujeres era evidente y bastante visible ya que tenemos documentos que intentan demostrar también que la obra de MDA fue censurada, entre otras cosas, porque estaba escrita por una mujer.

Por último, en la declaración, los misterios son criticados «se trompe du moins elle-même, en voulant faire passer des fables, des badineriesm, des fictions $E$ des erreurs (...) pour des mystères qui luy ony été revelez (...)». No se creen que todo lo escrito forme parte del gran mundo de los misterios, es más, existe una desconfianza a creer en la mística, en lo revelado, máxima. Nos preguntamos si este pensamiento no sólo formaba parte de estos doctores sino de toda

26. Censure faite par la Faculté de Théologie de Paris, d'un livre qui a pour titre: La mystique cité de Dieu (...). A Marseille au nom de Jésus, avec Privilège du Roi, 1695. La censure de la Sorbonne, Paris, 1696, bilingüe, B.N. Impr. D. 6926.

27. Tanto las Universidades españolas (Salamanca o Alcalá) como extranjeras (Lovaina) escribirán manifiestos en contra de la decisión tomada por la Facultad de Teología de París.

28. La censure de la Sorbonne, Paris, 1696, bilingüe, B.N. Impr. D. 6926.

29. En una de las cartas el autor afirma saber que la Universidad no aprobaría ningún libro que estuviese escrito por mujeres. 
la Universidad o allende, ya que asistimos a un periodo bastante convulso en la mística y la desconfianza en ella es bastante plausible ${ }^{30}$.

Por consiguiente, parece que MDA, en Francia, desde este punto de vista, con su obra magna cumplía todas las características para ser censurada pero al estudiar de lleno los entresijos de la censura hemos podido obtener una serie de conclusiones que cambiarían este pensamiento que no descartamos, sino que al contrario, ayudó a que su obra fuese puesta en duda.

Para poder adentrarnos más en el mundo de la censura así como en el mundo de la Virgen, ya que, estudiando la censura tenemos acceso a otra fuente más y a otro modo de pensamiento, nos permite remitirnos a la fuente principal y tener «la otra cara de la moneda», además de poder leer opiniones sobre el libro y la censura.

La censura actúa como un «recordatorio» para los fieles y todos aquellos que conforman la Iglesia. Pero, lo que nos preguntamos es hasta dónde llega el límite de lo revelado y cómo pueden decidir lo que está sujeto a la creencia y a las escrituras y qué no.

\section{Los puntos más problemáticos de la Censura}

La Universidad de la Sorbona puso el límite de lo que se debía saber y lo que no con la MCD, según los doctores de la Universidad se había llegado demasiado lejos en lo que a la virgen respectaba. Es por ello que por medio de la censura de algunos párrafos de la obra se redactó y se pusieron por escrito los puntos claves de lo que los Doctores veían como un atentado a las verdades de la revelación. Entre los puntos más debatidos y censurados encontramos los siguientes: para empezar el por qué de escribir la obra. MDA en su primer capítulo deja claro una serie de cosas, entre ellas que las revelaciones vividas y el éxtasis que la humanidad en la que ella vive se encuentra «perdida» en lo que concierne a la fe, es por ello que la MCD aparece en el momento adecuado para ser «la luz», para encontrar el verdadero sentido de todo lo que rodea a esa humanidad y no es en realidad, tan claro. Es, en palabras de MDA, encontrar la «salvación eterna», ya que en esa salvación la respuesta se encuentra de todo y la guía, es la Virgen la que conforma ese todo, en ella se encuentra el refugio y la razón de lo revelado, es en su persona, su imagen y su divinidad donde la humanidad puede salvarse de un trágico final.

Este punto es crucial ya que asistimos a una aparición o reaparición de la Virgen que demuestra una especie de «reencarnación» en la figura mariana

30. HAZARD, Paul. La crise de la conscience européenne, 1680-1715. Paris, Le livre de Poche, 1994. 
bastante significativo. Es un momento de afirmación o reafirmación del poder de la Virgen dentro de la Iglesia y dentro de la sociedad.

Evidentemente esta «reaparición» o aparición no gusta dentro de un grupo de doctores de la Sorbona de París y se censura este poder aludiendo a la falsedad de los misterios que le han sido revelados a MDA.

Otro de los puntos más importantes dentro de la censura es la Inmaculada Concepción. Es entre gran misterio en el que nuestra autora basa todos los demás, de ahí su importancia. La concepción de la Virgen ha sido objeto de debates interminables. Las primeras ideas de que la Virgen fue concebida sin pecado las encontramos en los autores del siglo IV, ya que ellos la empezaron a llamar «Santa». En el protoevangelio de Santiago se afirmaba que María fue Santa desde que nació y que pudiese ser que ella fuese concebida virginalmente. Orígenes y Tertuliano dijeron que la concepción de María fue un hecho interesante, ya que ella misma no tenía una fe absoluta en lo que el ángel le había comentado sobre la concepción sin pecado del mesías, del salvador. Este hecho puede demostrar una especie de «reclamo» humano, ya que puede verse como un acercamiento a una realidad más certera, a explicar que María fue humana antes que divina.

Después de este resumen de ideas es en el Concilio de Bâle que tuvo lugar el 17 de septiembre de 1439 donde definieron la Inmaculada Concepción «de acuerdo con el culto de la Iglesia, de la fe católica, de la razón y de las Santas Escrituras $»^{31}$. El Papa Sixto IV aprobó la creencia de la Inmaculada Concepción y animó a que se celebrase su fiesta. Clemente XI llegará un poco más lejos, el ordenará que su fiesta se celebre por todo el mundo. Pero el momento en el que el debate termina viene de la mano de Pio IX que en la Bula Ineffabilis Deus del 8 de diciembre de 1854 se afirmó que «desde el primer instante de su concepción, por gracia y privilegios únicos de Dios todopoderoso, la bienhereuse Virgen María ha sido en consideración de los méritos de Jesucristo, Salvador del género humano, preservada pura de toda traza de pecado original $»^{32}$.

El que María fuese concebida sin pecado alguno es una de las cualidades de las que anteriormente mencionábamos, cualidad que la hizo al final divina y diferente a las demás mujeres.

Otro de los puntos más discutidos y en el que MDA, parece ser, cometió un error, fue en el tema de la adoración. La adoración es el acto de honorar de una manera «especial», sin límites, a Dios, rindiéndole sumisión a causa de la

31. Lacoste, J.Y. Dictionnaire critique de théologie. Paris, PUF, 1998.

32. Ibidem

Feminismo/s 20, diciembre 2012, pp. 297-313 
grandeza del mismo. La Sorbona critica que MDA haya utilizado este término para adorar a la Virgen. Mateo decía que «vous adorerez le Seigneur votre Dieu et ne servirez que lui seul». Pero debemos decir que en la figura de Dios están comprendidos no sólo Dios, sino la Santa Trinidad, por ejemplo. Aquí debíamos preguntarnos dónde se encuentra la Virgen. Teóricamente la adoración puede ser utilizada para personas que tengan una especie de conexión con Dios pero «la Iglesia no lo permite para evitar la confusión de creer que la adoración se da a la persona $\star^{33}$. Por esta razón, no se permite adorar la Virgen sino venerarla como a los Santos.

¿Qué intentó con esto MDA? ¿Cómo una persona religiosa que tenía asimilados los puntos más importantes de la teología pudo cometer «esos errores»? Esta es una prueba más de lo que ansiaba MDA, no que la Virgen tuviese un papel protagonista, sino que tuviese voz y que ocupase un lugar que según ella le correspondía como Madre, como mujer y como la Reina de la cual ella hablaba.

Otro de los errores que se supone cometió fue afirmar que la Virgen había sido elevada varias veces al cielo. También es interesante ver como la Universidad arremete con lo que cuenta MDA sobre los padres de María, Joaquín y Ana. Nuestra autora da muchos más detalles sobre sus padres que en las Escrituras, ya que MDA empieza a contar la vida de la Virgen no desde que nace, sino desde que ella se encuentra en el vientre de Ana.

En resumidas cuentas estos fueron los errores más «fuertes» que cometió la madre Ágreda.

\section{Conclusión}

Estos errores, estudiados más ampliamente, nos hacen ver como la censura es en sí superficial y que respondió más a fines políticos que religiosos. También puede hacernos reflexionar sobre cómo los hombres doctores al leer la obra la vieron, ya que estaban ante una gran fuerza «femenina» en la que una mujer puso en relieve a otra mujer, al lado de Dios. Lo que es certero es que hubo un debate en torno a MDA y más en torno a su MCD y que se volvía a preguntar sobre la Virgen y, más aún, que les hacía replantearse la vida de la misma Virgen.

Parece ser que la obra de MDA era necesaria para los fieles que quisiesen saber más acerca de la vida de un personaje fascinante. Se llegó a hablar de la obra de MDA como el Evangelio que vendría a completar a todos los demás.

33. Ibidem.

Feminismo/s 20, diciembre 2012, pp. 297-313 
Quizá la censura fue el modo más rápido de que la obra de MDA se diese a conocer en todo el mundo, así que, lo que había conseguido la Sorbona había sido «dañar» a la obra y a su autora, pero al ver las respuestas a la censura podemos concluir que elevó tanto la dignidad e importancia de la Virgen María como el de su autora ya que el libro se convirtió en la época moderna en uno de los más impresos.

\section{Referencias Bibliográficas}

Historia de las mujeres y de género

THÉBAUD, Françoise. Écrire l'histoire des femmes et du genre, Paris, ENS éditions, 2007

Perrot, Michelle. Mon histoire des femmes, Paris, Seuil, Points Histoire, 2006

Perrot, Michelle. Les femmes ou les silences de l'Histoire, Paris, Champs Flammarion, 1998

Albistur, Maité; Armogathe, Daniel. Histoire du féminisme français du moyen âge à nos jours. Paris. Ed. Des femmes. 1998

Martino, Giulio; BRUZZESE, Marina. Las filósofas, Madrid, Cátedra, 2000.

Las mujeres en el Antiguo Régimen

BeAuvalet-Boutourie, Scartlett. Les femmes à l'époque moderne, Paris, Belin, 2003 Histoire des femmes en Occident, sous la direction de Georges Duby et Michelle Perrot, Paris, Plon, t.3 (XVIe-XVIIIe siècles), sous la direction de Nathalie Zemon DAVIS et Arlette FARGE, 1991

De Courcelles, Dominique, VAl JUlian, Carmen. Des femmes et des livres. France et Espagne, XIV-XVIIe siècle,Paris, École de Chartres, 1999

MARQUeZ de la Plata y FERrandiz, Vicenta. Mujeres pensadoras, místicas, científicas y heterodoxas, Madrid, Castalia, 2008

RaCine, Nicole; TREBITSCH, Michel. Intellectuelles. Du genre en histoire des intellectuelles. Paris, Éditions complexe, 2004

REYNIER, Gustave. La femme au XVIIe siècle, Paris, Ed. Jules Tallandier, 1929

VIENNOT, Eliane. La France, les femmes et le pouvoir. Les résistances de la société (XVIIe-XVIIIe siècles). Paris, Perrin, 2008

Historia sobre las religiosas y sobre la Virgen María

Delfosse, Annick. «La Vierge Marie, une figure polymorphe du catholicisme». Dossiers de la Bibliothèque royale de Belgique, 26 (2005), pp. 75-96. 
DELFOSSE, Annick. «La Vierge comme protectrice des Pays-Bas méridionaux dans les livrets de pèlerinage marial au XVIIe siècle». Revue Belge Philologie Histoir 80 (2002), pp. 1225-1241

Bernos, Marcel. Femmes et gens d'Église dans la France Classique, XVIIe-XVIIIe siècles, Paris, Éditions du cerf, 2003

POUTRIN, Isabelle. le voile et la plume: autobiographie et sainteté fémenine dans l'époque moderne. Madrid, Casa de Velázquez, 1995

FERRÚs, Beatriz : «Máscaras de cera: vida, autobiografía y retrato en el mundo conventual». Extravío, Revista electrónica de literatura comparada, 2007.

MORAND, Frédérique : «El papel de las monjas en la sociedad española del setecientos». Cuadernos de historia moderna, (2004), pp. 45-64

MORAND, Frédérique : «Testigos privilegiados en el ámbito urbano : las monjas del convento de Santa María en Cádiz o la creación femenina en clausura como posible fuente histórica». Hispania. Revista española de Historia, No 224 (2006), pp. 1019-1044

Obras sobre la época moderna

Carpentier, Jean; Lebrun, François. Histoire de France. Paris, Seuil, 2001.

CORVESIER, André. La France de Louis XIV. Ordre intérieur et place en Europe. Paris, Sedes. 1994

MARTinez Ruíz, Enrique ; GimÉnEz, Enrique ; Armillas, José A ; Maqueda, Consuelo. Introducción a la historia moderna. Madrid, Istmo, 2000.

NeVEu, Bruno. Lerreur et son juge. Nápoles, Bibliópolis, 1993.

LE BRUN, Jacques: «Censure préventive et littérature religieuse en France au début du XVIIIe siècle», Revue d'histoire religieuse de l'Église de France. Tome 61. No 167 (1995), pp. 201-225

Obras sobre Marie de Ágreda

Página web: www.mariadeagreda.org/

CAMBOLAS, François. Marie d'Agreda, Paris, France Europe, 2003

FERRÚs, Beatriz : «Mayor Gloria de Dios es que lo sea una mujer...Sor María de Jesús de Ágreda y Sor Francisca de la Concepción del Castillo (sobre la escritura conventual en los siglos XVI-XVII). Revista de Literatura, $N^{\circ} 139$, (2008), pp. 31-46

MARCO, Jaime: «Astronomía y salvación en la España de los Austrias : el tratado de la mapa » de Sor María de Jesús de Ágreda», La ciencia en el Monasterio del Escorial : Actas del simposium, (1994). pp. 649-666

SERRANO y SANZ. Apuntes para una biblioteca de escritoras españolas desde el año 1401 al 1833, Madrid, Suc. Rivadeneyra, 1903-1905 (biographie de Marie d'Agreda) 